\title{
Factors Influencing Disease Progression in Patients with Head and Neck Melanoma
}

\author{
UGUR USLU $^{1}$, GEROLD SCHULER $^{1}$ and HELMUT BREUNINGER ${ }^{2}$ \\ ${ }^{1}$ Department of Dermatology, Universitätsklinikum Erlangen, \\ Friedrich-Alexander-University Erlangen-Nürnberg (FAU), Erlangen, Germany; \\ ${ }^{2}$ Department of Dermatology, Eberhard Karls University Tübingen, Tübingen, Germany
}

\begin{abstract}
Background: Histological parameters as well as the status of sentinel lymph node are known to be strong prognostic factors in patients with melanoma. Patients and Methods: In this study, we retrospectively analyzed 1,384 patients who were diagnosed with head and neck melanoma between 1976 and 2010 regarding prognostic factors [tumor thickness, level of invasion, sentinel lymph node (SLN) status, ulceration, histological subtype, localization, and gender], overall survival, and disease-free survival. Results: Patients who developed metastases had a significantly thicker tumor than patients without metastases. Additionally, a thicker tumor was often associated with a higher level of invasion (Clark level). There was no overall survival benefit in patients who underwent SLN dissection when compared to patients who did not ( $p=0.07)$. Compared to SLN-negative patients, patients with SLN involvement had a significantly shorter disease-free period $(p<0.001)$ and shorter overall survival time $(p<0.001)$. Conclusion: In summary, tumor thickness is the most important prognostic factor. SLN dissection does not affect the overall survival of patients with melanoma. However, a positive SLN is a marker for a worse outcome in these patients.
\end{abstract}

Melanoma metastasizes most commonly via lymphatic routes (1). Subsequently, surgical control of lymph node (LN) metastases has become a common procedure. The initial aim of this procedure is presumably to curtail further dissemination of the cancer and thereby to improve patient prognosis (2-4).

Correspondence to: Dr. med. Ugur Uslu, MD, Friedrich-AlexanderUniversity Erlangen-Nürnberg (FAU), Department of Dermatology, Universitätsklinikum Erlangen, Ulmenweg 18, D-91054 Erlangen, Germany. Tel: +49 091318535000, e-mail: ugur.uslu@uk-erlangen.de

Key Words: Cancer, prognostic markers, tumor thickness, lymphadenectomy, neck dissection, sentinel lymph node dissection, survival.
In the past, every patient with head and neck melanoma (HNM) of intermediate thickness underwent prophylactic radical neck dissection (ND) with surgical removal of all cervical lymph node chains $(5,6)$. Non-lymphatic structures, such as muscle, blood vessels and nerves, are often compromised in this process, making long-term morbidity from this procedure an issue. Additionally, several studies have suggested no benefit in overall survival of such a procedure $(7,8)$. Therefore, selective and modified ND in cases of positive sentinel lymph node (SLN) or regional LN metastases was developed and is now the treatment of choice $(2,4,9,10)$. This newer procedure allows the preservation of non-affected LN groups, as well as of non-lymphatic structures in order to minimize complications.

Today, SLN dissection is recommended in all patients with melanoma with a tumor thickness of $1 \mathrm{~mm}$ or more. A tumor thickness of at least $1 \mathrm{~mm}$ is known to increase the risk of metastasis significantly (11). Besides tumor thickness, the status of the SLN is known to be a strong prognostic factor for prognosis of melanoma and was, therefore, included in the staging system for melanoma by the American Joint Committee on Cancer (12-14). However, the benefit of SLN dissection remains controversial, as improvement in overall survival has not been demonstrated (15-17).

The aim of this retrospective study was to analyze the progression of disease in patients diagnosed with HNM as well as whether any survival benefit is obtained from $\mathrm{LN}$ procedures in such patients. We analyzed and compared different groups with respect to prognostic factors (tumor thickness, level of invasion, ulceration, histological subtype, localization and gender), overall survival and disease-free survival.

\section{Patients and Methods}

A total of 1384 patients with primary cutaneous HNM were retrospectively reviewed. All patients were taken from the Central Malignant Melanoma Registry of Tubingen University, Department of Dermatology, which contains data on more than 9000 patients 


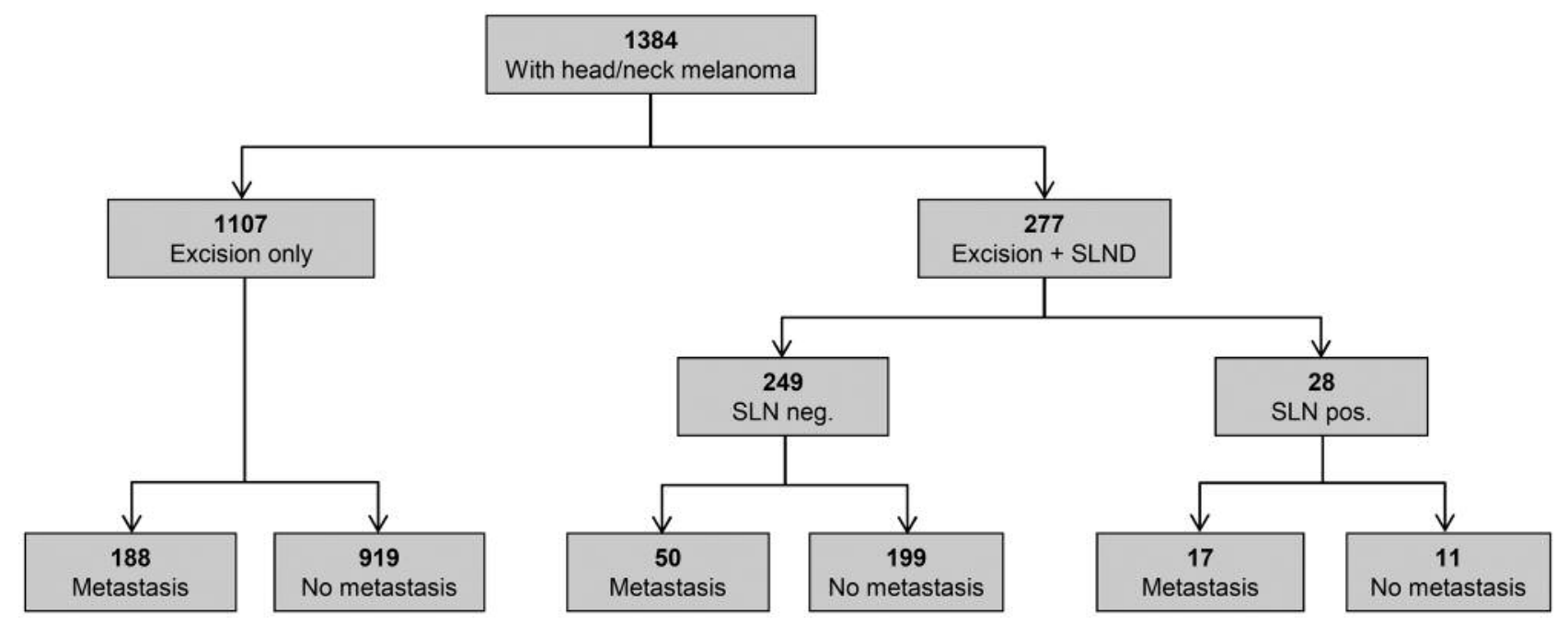

Figure 1. Overview of the whole database of the study (n=1,384). While 60.7\% (n=17) of sentinel lymph node (SLN)-positive patients developed metastases, the rate was only $20.1 \%(n=50)$ in the SLN-negative group. In comparison, $17 \%(n=188)$ of all patients without SLN dissection (SLND) developed metastases.

diagnosed with and treated for melanoma in southwest Germany since 1976. Of these, we included all cases of primary HNM in our analysis. The database includes data spanning 1976-2010. All patients, including those who had chemotherapy or radiation therapy to their nodal basins, underwent follow-up examinations as per the recommendations of the German Society of Dermatology $(18,19)$.

Data on patient demographics (gender, date of birth, age), primary tumor characteristics (location, date of diagnosis, date of metastasis), histological features (histological subtype, tumor thickness, level of invasion, ulceration) and the surgical treatment (excision of primary tumor, SLN dissection, ND) were obtained and analyzed. The location of the primary melanoma was classified under three anatomical sites: face, neck, and other. The histological subtype was classified under four categories: superficial spreading melanoma, nodular melanoma, lentigo maligna melanoma (LMM) and other. Histological tumor thickness (Breslow classification) and level of invasion (Clark level) were determined in all cases. Metastases were classified as satellite/in-transit metastases, regional LN metastases, and distant metastases. Patients with positive SLN and patients who developed regional LN metastases were recommended to undergo ND.

This study compared the following groups: Patients with SLN dissection vs. patients without SLN dissection; SLN-positive patients $v s$. SLN-negative patients; patients who underwent ND $v s$. patients who refused to do so.

All statistical analyses was performed with the Statistical Package for Social Science (SPSS) version 11.5 (SPSS, Chicago, IL, USA). Comparisons of variable distributions between groups were performed by using $t$-test and Cchi-square test. All differences were considered significant at $p \leq 0.05$.

The Kaplan-Meier method was used to analyze disease-free survival, defined as survival without evidence of metastasis or recurrence, and overall survival, defined as the survival until death from primary melanoma. In order to analyze the disease-free and overall survival, the date of excision of the primary melanoma was used as the starting point. The date of first metastasis or recurrence was used as the end-point for disease-free survival, and the date of the latest follow-up visit or death due to primary melanoma as the end-point for overall survival. The log-rank-test was used to compare and analyze the significance of disease-free and overall survival of two comparative groups. Again, all differences were considered significant at $p \leq 0.05$.

\section{Results}

SLN dissection group vs. non-SLN dissection group. Overall, $277(20 \%)$ out of 1,384 patients with primary cutaneous HNM underwent SLN dissection. The other 1107 (80\%) underwent excision of the primary melanoma only (Figure 1). In the SLN dissection collective, there were significantly more male patients when compared to the non-SLN dissection group $(p=0.002)$. There was also significantly thicker tumor $(p<0.001)$, a higher level of Invasion $(p<0.001)$, and more ulcerations $(p<0.001)$ in the SLN dissection group. The histological subtype $(p<0.001)$ and localization $(p<0.001)$ differed between the two collectives significantly as well: There was a higher rate of LMM in the non-SLN dissection group when compared to the SLN dissection group (51.6\% vs. $32.5 \%$ ), a lower rate of nodular melanoma (12.5\% vs. 26.4\%) and a higher rate of localization in the face $(57.9 \% \mathrm{vs.} .43 .3 \%)$. The overall survival for the both groups did not differ $(p=0.07)$ (Figure 2). However, the disease-free survival was significantly worse in the SLN dissection group $(p<0.001)$.

SLN-positive group vs. SLN-negative group. Overall, 28 (10.1\%) out of 277 patients who underwent SLN dissection were found to have a positive SLN, of whom 23 underwent 


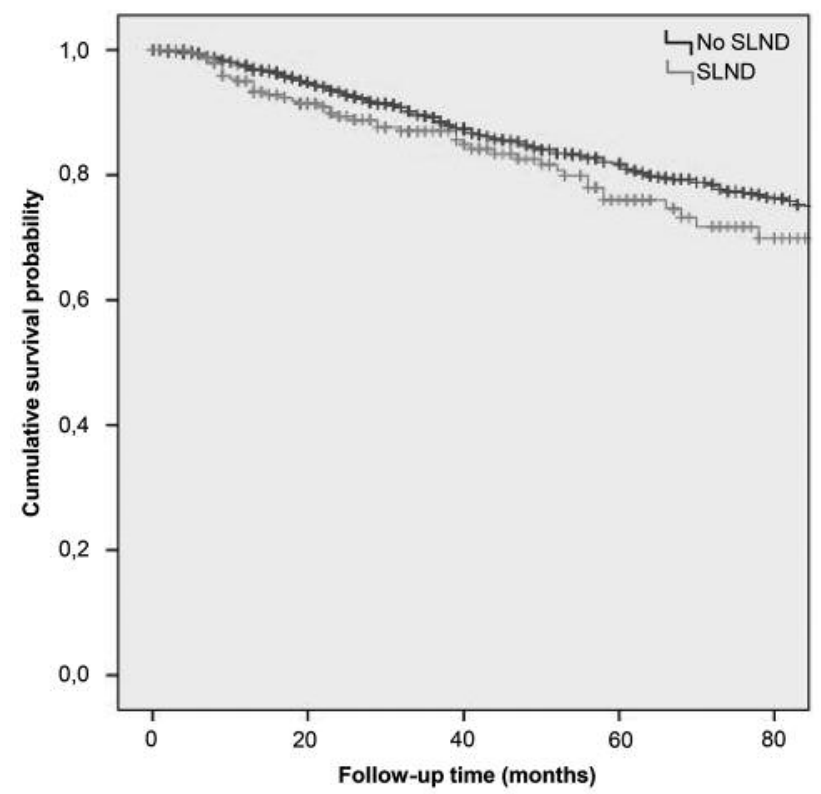

Figure 2. Overall survival of patients who underwent sentinel lymph node dissection ( $S L N D, n=277$ ) compared to patients who underwent excision of primary melanoma only (no SLND, $n=1107$ ). Patients with $S L N D$ did not differ in regard to overall survival when compared to patients who did not undergo SLND ( $p=0.07)$.

ND following SLN dissection (Figure 1, Table I). The other five SLN-positive patients refused ND. A total of 249 patients $(89.9 \%)$ were SLN-negative (Figure 1, Table I). Out of the 23 SLN-positive patients who also underwent ND, seven $(31.4 \%)$ did not develop metastases, the other 16 patients $(69.6 \%)$ developed one or more metastases: satellite/in-transit metastases in 10, regional LN metastases in seven and distant metastases in 13. On the other hand, one out of the five SLN-positive patients who refused ND developed metastasis (distant metastases).

Tumor thickness and the level of invasion differed between the collectives: The SLN-positive group had a significantly thicker tumor $(p=0.006)$ and a higher level of invasion $(p=0.008)$ when compared to the SLN-negative group (Table I). No difference between the two groups was seen in gender $(p=0.1)$, localization $(p=0.7)$, histological subtype $(p=0.054)$ or ulceration $(p=0.3)$ (Table I). Patients with a positive SLN had poorer disease-free $(p<0.001)$ and overall $(p<0.001)$ survival when compared to the SLNnegative patients.

$N D$ vs. refusal of $N D$. Overall, 79 out of all patients who were SLN-positive or who developed LN metastases underwent ND, 51 patients refused (Figure 1). Groups did not differ with respect to gender $(p=0.1)$, localization $(p=0.6)$, histological subtype $(p=0.1)$, tumor thickness
Table I. Comparison of patients with primary cutaneous head and neck melanoma with positive sentinel lymph node (SLN) compared to patients with negative SLN with respect to prognostic factors.

\begin{tabular}{lccc}
\hline Characteristic & $\begin{array}{c}\text { SLN-positive, } \\
\mathrm{n}(\%) \\
(\mathrm{n}=28)\end{array}$ & $\begin{array}{c}\text { SLN-negative, } \\
\mathrm{n}(\%)\end{array}$ & $p$-Value \\
& $(\mathrm{n}=249)$ & \\
\hline Gender & & & 0.1 \\
$\quad$ Female & $7(25.0 \%)$ & $100(40.2 \%)$ & \\
$\quad$ Male & $21(75.0 \%)$ & $149(59.8 \%)$ & \\
Tumor thickness & & & 0.006 \\
$<1,0 \mathrm{~mm}$ & $0(0.0 \%)$ & $20(8.0 \%)$ & \\
$1.00-2.00 \mathrm{~mm}$ & $6(21.4 \%)$ & $107(43.0 \%)$ & \\
$2.010-4.00 \mathrm{~mm}$ & $12(42.9 \%)$ & $86(34.5 \%)$ & \\
$>4.00 \mathrm{~mm}$ & $10(35.7 \%)$ & $36(14.5 \%)$ & 0.008 \\
Level of invasion $\$$ & & & \\
III & $1(3.6 \%)$ & $16(6.4 \%)$ & \\
IV & $14(50.0 \%)$ & $187(75.1 \%)$ & \\
V & $8(28.6 \%)$ & $26(10.4 \%)$ & 0.054 \\
Histological subtype & & & \\
SSM & $8(28.6 \%)$ & $59(23.7 \%)$ & \\
NM & $13(46.4 \%)$ & $60(24.1 \%)$ & \\
LMM & $3(10.7 \%)$ & $87(34.9 \%)$ & \\
Other & $4(14.3 \%)$ & $43(17.2 \%)$ & \\
Localization & & & 0.7 \\
Face & $11(39.3 \%)$ & $109(43.8 \%)$ & \\
Neck & $3(10.7 \%)$ & $34(13.7 \%)$ & \\
Other & $14(50.0 \%)$ & $106(42.6 \%)$ & 0.3 \\
Ulceration* & & & \\
Yes & $10(35.7 \%)$ & $58(23.3 \%)$ & \\
No & $11(39.3 \%)$ & $130(52.2 \%)$ & \\
\hline
\end{tabular}

SSM: Superficial spreading melanoma, NM: nodular melanoma, LMM: lentigo maligna melanoma. Unknown status in a total of $* 68(24.5 \%)$, and $\S_{25}(9.0 \%)$ cases.

$(p=0.7)$, level of invasion $(p=0.3)$ or ulceration $(p=0.3)$. There was also no difference in disease-free $(p=0.4)$ and overall survival $(p=0.5)$.

\section{Discussion}

A total of 1,384 patients were analyzed for the current study: $20 \%$ of these patients underwent SLN dissection $(n=277)$. Only $10.1 \%$ of the SLN dissection group had a positive SLN $(n=28)$. In prior studies, which analyzed the SLN dissection in other parts of the body, the rate of SLN-positive patients varied between $12 \%$ and $20 \%$ (20), which is higher than in the current study. A possible reason is the high rate of LMM in our study: $47.8 \%(n=661)$ of the 1,384 patients were diagnosed with LMM, which is known to metastasize less commonly compared to other subtypes $(21,22)$. Another possibility is that the SLN in HNM can be located contralaterally, and thereby remains undetected (23). Additionally, compared to other dermatological centers, 
Table II. Overview of study results indicating the factors which influence or do not influence the progression of disease in patients with head and neck melanoma.

Association

\author{
Influencing factor \\ Tumor thickness \\ Level of invasion \\ Histological subtype \\ Localization \\ Gender \\ Positive SLN \\ Non-influencing factor \\ SLN dissection \\ Neck dissection
}

SLN: Sentinel lymph node.

sonography has been used as a standard examination at the Dermatology Department of Tubingen University to detect regional LN metastases. All LN metastases detected by sonography were considered as macro-metastases and these patients underwent ND without SLN dissection, thereby reducing again the total number of SLN dissections in our study. Unfortunately, the current study does not include data regarding LN metastases detected by ultrasound. However, it is known that $30 \%$ of $\mathrm{LN}$ metastases detected by sonography are not detected by palpation (24). On these grounds, sonography may ensure early detection of LN metastases, thereby improving the prognosis of patients with melanoma significantly, and should be a routine examination technique at dermatological centers.

In the current study, patients who underwent SLN dissection did not differ in regard to overall survival when compared to the group of patients without SLN dissection, which confirms the lack of prognostic significance of SLN dissection (Table II). However, the status of the SLN is part of the classification of cutaneous melanoma, as patients with positive SLN have a significantly worse prognosis than SLNnegative patients (12-14). Our study confirmed this finding: The disease-free survival as well as the overall survival was better in SLN-negative patients when compared to SLNpositive patients. In addition, the rate of recurrence was better in SLN-negative patients: While $60.7 \%$ of SLNpositive patients developed metastases, the rate was only $20.1 \%$ in the SLN-negative group. In comparison, $17 \%$ of all patients without SLN dissection developed metastases.

The Multicenter Selective Lymphadenectomy Trial 1 (MSLT-1) analyzed the differences of patients with melanoma with excision of the primary melanoma followed by SLN dissection compared to patients who underwent excision of the primary melanoma only (25). Tumor thickness of the primary melanoma was $1 \mathrm{~mm}$ or more (25). Most of our results confirmed the findings of MSLT-1. In both studies, the overall survival of the two groups (SLN dissection $v s$. non-SLN dissection) did not differ (25). However, there was better disease-free survival in the SLN dissection group of the MSLT-1 (25), which differs from our study. In the current study, we also considered patients with tumor thickness of less than $1 \mathrm{~mm}$, thereby increasing the total number of those with smaller melanomas. As a result, the non-SLN dissection group had better disease- free survival. In both studies, the SLN-negative group had better overall and disease-free survival when compared to the SLNpositive group, which confirms the significance of the SLN status (25). Moreover, as in our study, in MSLT-1 the rate of metastasis in the SLN-negative group correlated with the rate in the non-SLN dissection group (19.8\% vs. $20.3 \%$ in the MSLT-1, 20.1\% vs. 17\% in our study) (25).

A total of 130 patients in this study were found to have LN metastases: 28 SLN-positive patients, 24 SLN-negative patients and 99 non-SLN dissection patients. Out of the 130 patients, only $79(60.8 \%)$ had undergone ND, the other 51 patients had (39.4\%) refused. Reasons for refusal included old age, concerns of postoperative complications or known multiple metastases including distant metastases. The two groups did not differ with regard to prognostic factors or overall survival, which shows the lack of prognostic benefit of this procedure (Table II). Multiple studies in the past have shown similar results $(3,26)$. There were no significant differences with respect to overall survival between the groups with selective lymphadenectomy compared to groups with removal of the affected lymph nodes only $(3,26)$. Moreover, especially in the time before SLN dissection, all patients with 
melanoma underwent prophylactic elective lymphadenectomy (27). However, $80-88 \%$ of all patients who underwent elective lymphadenectomy did not have LN metastases at all (27). These patients did not actually benefit from the procedure and were in fact exposed to possibly high postoperative risk (27).

In this study, we confirmed that tumor thickness is the most important prognostic factor (Table II). Patients who developed metastases had a significantly thicker tumor than patients without metastases. Additionally, a thicker tumor was often associated with a higher level of invasion (Clark level). However, the significance of the level of invasion for melanoma is discussed controversial: Prior studies showed that there is no prognostic significance of the level of invasion in melanoma with tumor thickness of $1 \mathrm{~mm}$ or less $(28,29)$. We confirmed that the prognosis of melanoma is associated with the histological subtype of the malignancy: In groups with no metastases, the patients were most likely found to have a LMM, whereas in groups with metastases, most likely nodular melanoma was seen $(21,22)$. This study also confirms that localization and gender play an important role in the prognosis and treatment of cutaneous melanoma: The primary tumor of patients who did not develop metastases was mainly localized in the face $(3,30)$. Male gender was associated with worse prognosis (Table II). Ulceration is considered another prognostic factor; however, it was not possible to make a conclusion as to its prognostic significance in this study because ulceration has only been documented by the Central Malignant Melanoma Registry of Tubingen University since 1996.

In summary, the current large study of cutaneous HNM confirmed the finding of melanomas at other sites of the body. Tumor thickness is the most important prognostic factor. SLN dissection does not affect the overall survival of patients with melanoma. However, a positive SLN is a marker for a worse outcome in these patients. The rate of SLN positivity was lower than that at the axilla or groin for example. This may be explained by the large number of LMMs in the head and neck region, which are known to metastasize less likely compared to other subtypes. Regional lymphadenectomy of the neck (ND) in the case of LN metastases does not affect the overall survival and thereby seems not to be an effective procedure in achieving this oncological goal.

\section{References}

1 Emmett MS, Symonds KE, Rigby H, Cook MG, Price R, Metcalfe C, Orlando A and Bates DO: Prediction of melanoma metastasis by the Shields index based on lymphatic vessel density. BMC Cancer 10: 208, 2010.

2 Balch CM, Soong SJ, Atkins MB, Buzaid AC, Cascinelli N, Coit DG, Fleming ID, Gershenwald JE, Houghton A Jr, Kirkwood JM, McMasters KM, Mihm MF, Morton DL, Reintgen DS, Ross MI, Sober A, Thompson JA and Thompson JF.: An evidencebased staging system for cutaneous melanoma. CA Cancer J Clin 54: 131-149, 2004.
3 Balch CM, Gershenwald JE, Soong SJ, Thompson JF, Atkins MB, Byrd DR, Buzaid AC, Cochran AJ, Coit DG, Ding S, Eggermont AM, Flaherty KT, Gimotty PA, Kirkwood JM, McMasters KM, Mihm MC Jr, Morton DL, Ross MI, Sober AJ and Sondak VK: Final version of 2009 AJCC Melanoma Staging and Classification. J Clin Oncol 27: 6199-6206, 2009.

4 Morton DL, Thompson JF, Cochran AJ, Mozzillo N, Nieweg OE, Roses DF, Hoekstra HJ, Karakousis CP, Puleo CA, Coventry BJ, Kashani-Sabet M, Smithers BM, Paul E, Kraybill WG, McKinnon JG, Wang HJ, Elashoff R and Faries MB: Final trial report of sentinel-node biopsy versus nodal observation in melanoma. N Engl J Med 370: 599-609, 2014.

5 Fadaki N, Li R, Parrett B, Sanders G, Thummala S, Martineau L, Cardona-Huerta S, Miranda S, Cheng ST, Miller JR 3rd, Singer M, Cleaver JE, Kashani-Sabet $M$ and Leong SP: Is head and neck melanoma different from trunk and extremity melanomas with respect to sentinel lymph node status and clinical outcome? Ann Surg Oncol 20: 3089-3097, 2013.

6 Cascinelli N, Morabito A, Santinami M, MacKie RM, Belli F: Immediate or delayed dissection of regional nodes in patients with melanoma of the trunk: a randomised trial. Lancet 351 : 793-796, 1998.

7 Veronesi U, Adamus J, Bandiera DC, Brennhovd IO, Caceres E, Cascinelli N, Claudio F, Ikonopisov RL, Javorskj VV, Kirov S, Kulakowski A, Lacoub J, Lejeune F, Mechl Z, Morabito A, Rodé I, Sergeev S, van Slooten E, Szcygiel K and Trapeznikov NN: Inefficacy of immediate node dissection in stage 1 melanoma of the limbs. N Engl J Med 297: 627-630, 1977.

8 Schachter J, Laish A, Mekhmandarov S, Feinmesser M, Fenig E, Tamir G and Gutman H: Standard and nonstandard applications of sentinel node- guided melanoma surgery. World J Surg 24: 491-494, 2000.

9 Cascinelli N, Belli F, Santinami M, Fait V, Testori A, Ruka W, Cavaliere R, Mozzillo N, Rossi CR, MacKie RM, Nieweg O, Pace $\mathrm{M}$ and Kirov K: Sentinel lymph node biopsy in cutaneous melanoma: the WHO Melanoma Program experience. Ann Surg Oncol 7: 469-474, 2000

10 Morton DL and Cochran AJ: The case for lymphatic mapping and sentinel lymphadenectomy in the management of primary melanoma. Br J Dermatol 151: 308-319, 2004.

11 Buettner P, Garbe C and Guggenmoos-Holzmann I: Problems in defining cut-off points of continuous prognostic factors: example for tumor thickness in primary cutaneous melanoma. J Clin Epidemiol 50: 1201-1210, 1997.

12 Kettlewell S, Moyes C, Bray C, Soutar D, MacKay A, Byrne D, Shoaib T, Majumder B and MacKie R: Value of sentinel node status as a prognostic factor in melanoma: prospective observational study. BMJ 332: 1423, 2006.

13 Yee VS, Thompson JF, McKinnon JG, Scolyer RA, Li LX, McCarthy WH, O'Brien CJ, Quinn MJ, Saw RP, Shannon KF, Stretch JR and Uren RF: Outcome in 846 cutaneous melanoma patients from a single center after a negative sentinel node biopsy. Ann Surg Oncol 12: 429-439, 2005.

14 Leiter U, Buettner PG, Bohnenberger K, Eigentler T, Meier F, Moehrle M, Breuninger H and Garbe C: Sentinel lymph node dissection in primary melanoma reduces subsequent regional lymph node metastasis as well as distant metastasis after nodal involvement. Ann Surg Oncol 17: 129-137, 2010. 
15 Möhrle M, Schippert W, Rassner G, Garbe C and Breuninger H: Is sentinel lymph node biopsy of therapeutic relevance for melanoma? Dermatology 209: 5-13, 2004.

16 Medalie N and Ackermann AB: Sentinel node biopsy has no benefit for patients whose primary cutaneous melanoma has metastasized to a lymph node and therefore should be abandoned now. Br J Dermatol 151: 298-307, 2004.

17 Balch CM and Cascinelli N: Sentinel- node biopsy in melanoma. N Engl J Med 355: 1370-1371, 2006.

18 Wagner JD, Gordon MS, Chuang TY and Coleman JJ: Current therapy of cutaneous melanoma. Plast Reconstr Surg 105: 177499, 2000.

19 Garbe C, Eigentler TK, Keilholz U, Hauschild A and Kirkwood JM: Systematic review of medical treatment in melanoma: current status and future prospects. Oncologist 16: 5-24, 2011.

20 Arens A, Osinga J, Schwipper V, Schober O, Tilkorn H and Liebau J: Sentinel lymph node dissection in patients with malignant melanoma Diagnostic and therapeutic standards. Chirurg 74: 665-70, 2003.

21 Garbe C, Büttner P, Bertz J, Burg G, d'Hoedt B, Drepper H, Guggenmoos-Holzmann I, Lechner W, Lippold A and Orfanos CE: Primary cutaneous melanoma. Identification of prognostic groups and estimation of individual prognosis for 5093 patients Cancer 75: 2484-2491, 1995.

22 Kuchelmeister C, Schaumburg- Lever G and Garbe C: Acral cutaneous melanoma in Caucasians: clinical features, histopathology and prognosis in 112 patients. Br J Dermatol 143: 275-280, 2000.

23 Hoetzenecker W, Guenova E, Böttinger TU, Häfner HM and Breuninger H: Mapping of specific sentinel node locations for skin cancer of the head. Eur J Dermatol 21: 354-358, 2011.

24 Blum A, Schlagenhauff B, Stroebel W, Breuninger H, Rassner $\mathrm{G}$ and Garbe C: Ultrasound examination of regional lymph nodes significantly improves early detection of locoregional metastases during the follow- up of patients with cutaneous melanoma: results of a prospective study of 1288 patients. Cancer 88: 2534-2539, 2000.
25 Morton DL, Hoon DS, Cochran AJ, Turner RR, Essner R, Takeuchi H, Wanek LA, Glass E, Foshag LJ, Hsueh EC, Bilchik AJ, Elashoff D and Elashoff R: Lymphatic mapping and sentinel lymphadenectomy for early- stage melanoma: therapeutic utility and implications of nodal microanatomy and molecular staging for improving the accuracy of detection of nodal micrometastases. Ann Surg Oncol 238: 538-549, 2003.

26 Balch CM, Soong SJ, Bartolucci AA, Urist MM, Karakousis CP, Smith TJ, Temple WJ, Ross MI, Jewell WR, Mihm MC, Barnhill RL and Wanebo HJ: Efficacy of an elective regional lymph node dissection of 1 to $4 \mathrm{~mm}$ thick melanomas for patients 60 years of age and younger. Ann Surg 224: 255-263, 1996.

27 Hohenberger W, Gohl J, Altendorf- Hofmann A and Meyer T: Lymph node dissections in malignant melanoma. Chirurg 67: 779-787, 1996.

28 Leiter U, Buettner PG, Eigentler TK and Garbe C: Prognostic factors of thin cutaneous melanoma: An analysis of the Central Malignant Melanoma Registry of German Dermatological Society. J Clin Oncol 22: 4376-4383, 2004.

29 Owen SA, Sanders LL, Edwards LJ, Seigler HF, Tyler DS and Grichnik JM: Identification of higher risk thin melanoms should be based on Breslow depth not Clark level IV. Cancer 91: 983991, 2001.

30 Retsas S, Henry K, Mohammed MQ and MacRae K: Prognostic factors of cutaneous melanoma and a new staging system proposed by the American Joint Committee on Cancer (AJCC): validation in a cohort of 1248 patients. Eur J Cancer 38: 511516, 2002.

Received May 16, 2017

Revised May 28, 2017

Accepted May 30, 2017 